\title{
16 Testing the Relevance of Major Social Enterprise Models in Central and Eastern Europe
}

\author{
Jacques Defourny, Marthe Nyssens \\ and Olivier Brolis
}

\section{Introduction}

Although the notions of social entrepreneurship, social entrepreneur and social enterprise have sometimes been considered as different facets of a same phenomenon, especially in the late 1990s and early 2000s, the last two decades have witnessed clear trends towards distinct research developments about social entrepreneurship (and the related term of social entrepreneur), on the one hand (Dacin et al. 2011; Santos 2012; Alegre et al. 2017, among many others), ${ }^{1}$ and social enterprise, on the other hand ${ }^{2}$ - though, of course, this does not mean that the boundaries between these two research fields are clear-cut. In addition to such trends, many conceptual debates are still taking place within each of both "sides", and in particular in the field of research on the concept of social enterprise (SE), which is at the heart of this book as well as of this final chapter. Indeed, the lack of a shared understanding and definition of social enterprise is today acknowledged by most of the researchers, and it even seems reasonable to speak of the "impossibility of reaching a unified definition of social enterprise".

In response to such conceptual diversity and sometimes confusion, various authors tried to identify categories or types of social enterprise and to propose basic typologies. Alter (2007) was among the first; she put forward various types of operational models, for instance in terms of relations between social enterprises' missions and economic activitieswhich can be, according to the terminology she proposed, missioncentric, mission-related or mission-unrelated. A bit later, Spear et al. (2009) identified four main types of social enterprise in the UK, according to the initiatives' origins and development paths. For the same country, Teasdale (2012) and Gordon (2015) stressed the diversity of discourses or "basic values" shaping SE models, while McMurtry and Brouard (2015) put forward a typology adapted to the Canadian context. For their part, relying mainly on an analysis of the US SE landscape, Young et al. (2016) proposed the metaphor of a "social enterprise zoo", in which different 
types of animals seek different things—-just like social enterprises, which differ significantly from each other in the ways in which they combine social and market goals.

When it comes to international comparative works, Kerlin (2013, 2017) adopted an institutional perspective inspired by the "social origins" theory developed by Salamon et al. (2000), identifying key features of macro-institutional frameworks to suggest how any set of socioeconomic and regulatory institutions at country level tends to shape a specific major SE model per country. Borzaga and Defourny (2001), for the countries that then made up the European Union; Nyssens (2006), for eleven EU countries; Borzaga et al. (2008), for Central and Eastern Europe; Defourny and Kim (2011), for Eastern Asia; and more recently, the European Commission (2020), for the whole of Europe, all made attempts at international comparative analyses, but-with one exception ${ }^{3}$ - these analytical grids did not rely on systematic data collection at the enterprise level.

Against such background, we developed a typology of SE models (Defourny and Nyssens 2017), which we also present in the introductory chapter of this book (see Section 2, about the second phase of the ICSEM Project). This typology, which is rooted in theoretical grounds provided by some inspiring works carried out by Gui (1991) and Hansmann (1996) on the very identity of the "third sector" ${ }^{4}$ highlighted four major SE models: the entrepreneurial non-profit (ENP), the social cooperative (SC), the social business (SB) and the public social enterprise (PSE).

The main objective of this final chapter is to test statistically, at the enterprise level, the relevance of this typology of SE models, on the basis of a dataset resulting from a field survey carried out on social enterprises. On such basis, we put forward the hypothesis that this typology is neither country-specific nor even, more broadly, context-specific. In other words, we will try to see to what extent each SE model may be identified across countries in Central and Eastern Europe and across world regions. In such broad perspective, we carried out the statistical testing both at the worldwide level and at the regional level, but in line with the whole content of this book, this final chapter of course focuses on Central and Eastern Europe and on the statistical exploitation of the data collected in this region.

This chapter is organised as follows. We first present the methodology adopted for the empirical survey that is at the very heart of this statistical work: we describe the key dimensions of social enterprise that were captured and the methodological choices that were made for this survey, which was carried out on 721 social enterprises operating in various world regions (Section 1). We then present the hierarchical cluster analysis that we carried out on the basis of such an outstanding dataset for Central and Eastern Europe (Section 2), before discussing the empirical results obtained, especially regarding the existence (or not) of our four 
theorised SE models (Section 3). Finally, we conclude in terms of policy implications (Section 4).

\section{The ICSEM Survey and Database}

All the researchers involved in the ICSEM Project first had to provide a "country contribution" about the SE landscape in their respective countries. Among other things, researchers were asked to identify and characterise the various SE types or categories they could observe (phase 1 of the ICSEM Project; for a more detailed description of this phase, see the introductory chapter in this volume). Two major distinctive features of this approach should be underlined here. First, no a priori strict definition of social enterprise was imposed for these national contributions. We broadly delineated the field of analysis as "made of organisations that combine an entrepreneurial dynamic to provide services or goods with the primacy of their social aims". The emphasis was put on the embeddedness of the SE phenomenon in local contexts. Secondly, most of the research was carried out by teams rather than by individual researchers, and this fostered discussion at the local or national level, thereby reducing the risks of biases induced by purely personal perceptions.

In a second phase, in order to address the lack of reliable datasets at enterprise level to undertake international comparative analysis, indepth information was collected about social enterprises on the basis of a common questionnaire. More precisely, ICSEM research partners interviewed the managers of three to five social enterprises that were deemed emblematic of each SE type identified in the project's first phase. The researchers were asked to collect information regarding more specifically the nature of the social mission or social aims, the type of economic model and the governance structure, as we hypothesised that these three dimensions particularly informed the diversity of social enterprises. Let us recall, in this regard, that the EMES SE ideal-type relies on these three dimensions. For each of them, a set of three indicators is put forward. It does not mean, though, that an organisation has to meet all the indicators in order to qualify as a social enterprise; the ideal-type is rather used as a yardstick for the comparison and grouping of observed organisations.

As a result, detailed data were collected in a rather homogenous way for 721 social enterprises from 43 countries. Needless to say, such a sample is by no way representative of the SE population across the world. Indeed, not only is the distribution across continents particularly uneven, with a quasi-absence of Africa; more fundamentally, the whole SE population is simply unknown, as there is no universal definition of social enterprise. $^{5}$

As given in Table 16.1, the nineteen European countries covered by the survey account for almost half of all the enterprises surveyed across the world (328 enterprises out of 721). Thanks to the high number of 
Table 16.1 Social enterprises covered by the ICSEM survey by region/country

\begin{tabular}{lll}
\hline Regions and countries & $\begin{array}{l}\text { No. of } \\
\text { countries }\end{array}$ & $\begin{array}{l}\text { No. of social } \\
\text { enterprises }\end{array}$ \\
\hline Europe & 19 & 328 \\
$\quad$ Western Europe & 12 & 164 \\
$\quad$ Central and Eastern Europe & 7 & 164 \\
$\quad$ Albania & & 30 \\
$\quad$ Croatia & & 12 \\
$\quad$ Czech Republic & & 20 \\
$\quad$ Hungary & & 30 \\
$\quad$ Macedonia & & 22 \\
$\quad$ Roland & & 11 \\
Asia & 9 & 39 \\
Latin America & 7 & 100 \\
USA, Canada, Australia and New Zealand & 4 & 162 \\
Middle East (Israel and United Arab Emirates) & 2 & 45 \\
Africa (Rwanda and South Africa) & 2 & 31 \\
Total & 43 & 55 \\
\hline
\end{tabular}

observed social enterprises in Europe, the statistical work could be carried out in separate ways for Western Europe (with 164 surveyed social enterprises from twelve countries) and Central and Eastern Europe (with 164 surveyed social enterprises from seven countries). In this volume dedicated to social enterprise in Central and Eastern Europe, we of course focus mostly on findings for this region. ${ }^{6}$

In spite of limitations in the collection of data at the enterprise level, we argue that our overall research strategy-which combines a theoretical typology and a quite demanding bottom-up empirical approach based on a field survey - constitutes a significant step towards capturing the diversity of SE models. The following step (phase 3 of the ICSEM Project) aimed to exploit the dataset built through the ICSEM survey in order to see if it provided empirical support to the typology of SE models mentioned earlier and described in more detail in Section 2 of the introductory chapter in this volume.

\section{A Hierarchical Cluster Analysis to Identify Major SE Categories}

For the purpose of carrying out a cluster analysis, we extracted quantitative and qualitative (nominal and ordinal) variables from the questionnaire. The ultimate goal was to describe each of the 164 social enterprises from Central and Eastern Europe along five major dimensions: (1) general identity (legal form, origin and accreditations); (2) social mission (mission's nature, relation with the social enterprise's main economic 
activity, price of the goods and services provided and type of innovation); (3) workforce composition (workers and volunteers); (4) financial structure in general and, more precisely, ways in which the social enterprise combines various types of resources; and (5) governance structure and rules regarding the allocation of surplus. As multiple choices and combinations of several choices were possible for many questions, we defined 141 variables.

Before undertaking a hierarchical cluster analysis (HCA) based on Ward's aggregation method, we had to solve two main issues. First, our database included both quantitative and qualitative variables, while HCA cannot be performed on qualitative variables. Secondly, we wanted each of the five pre-determined dimensions to have the same weight, which was not the case since some dimensions were composed by a higher number of variables than others. In order to overcome these problems, we, therefore, performed a multiple factorial analysis (MFA) on the 141 defined variables and selected six factors. Using MFA solved our two problems: first, it made it possible to give the same importance to each of the five pre-determined dimensions; secondly, it enabled us to describe each social enterprise through quantitative indicators only (the social enterprise's coordinates on each factor).

The optimal number of clusters $(n)$ resulting from the HCA corresponds to the number of clusters for which the sum of intra-cluster variances does not decrease significantly when $n+1$ clusters are considered. Based on that criterion, we identified five major clusters. ${ }^{7}$

\section{SE Models in Eastern and Central Europe: Which Profiles and Relevance?}

The key results of our statistical work are displayed in Table 16.2 (at the end of Section 3), where the five clusters are described through the various dimensions listed in the first column. The various clusters are analysed here with the following question in mind: to what extent do these clusters confirm or not the existence of our theorised SE models? Although Central and Eastern Europe displays SE patterns quite similar to the overall worldwide sample (Defourny et al. 2020), it is interesting to point out some distinctive features as well.

\subsection{Three Clusters Converging Towards an Entrepreneurial Non-Profit SE Model}

Three clusters (clusters 3, 4 and 5) gather more than half of the social enterprises in this Eastern sample and can be considered as "entrepreneurial non-profit social enterprises" (ENPs). One of them (cluster 5) gathers organisations providing mainly health and social services, whereas social enterprises in cluster 4 contribute to local development 
and those in cluster 3 are mainly driven by a mission of employment generation and may, therefore, be considered as work-integration social enterprises (WISEs).

The dominant legal forms in the cluster gathering "health and socialservices" ENPs (cluster 5) are those of non-profit organisation and foundation. Two-thirds of social enterprises in this cluster have been launched by a group of citizens or a third-sector organisation. The board holds, in most of the cases, the ultimate decision-making power; in one-third of the cases, a single person is the social enterprise's initiator, and he/she often independently manages the organisation. In almost $40 \%$ of social enterprises in this cluster, in case the activity is terminated, net assets go to another organisation with a similar social mission. These features are typical of NPOs, understood in a broad sense, including public-benefit foundations. Another major distinctive feature of social enterprises in this cluster is the fact that, even though they are medium-sized organisations, they are the largest organisations in the entire sample.

Only $24 \%$ of income comes from the market. Social enterprises in this cluster receive substantial public subsidies, and they also rely partially on philanthropy, including volunteering. Only one-fourth of these organisations sell their services at market price. Indeed, providing at least some services free of charge or at a price not covering most of the production costs is a widespread practice in this cluster.

Such resource mix could be seen as somehow surprising since a usual approach to social enterprise sees it as "a market solution to a social problem". For many scholars, however, among which those belonging to the EMES school of thought (Defourny and Nyssens 2010), the entrepreneurial dimension of social enterprise lies, at least partly, in the fact that the initiative bears a significant level of entrepreneurial risk, but not necessarily a market risk. In this broader perspective, the resource mix which can best support the social mission is likely to have a hybrid character, as it may combine trading activities with public subsidies and voluntary resources.

In a similar way, Maier et al. (2016) identify several dynamics which can characterise "NPOs becoming business-like", beyond the sole market character of financial resources: NPOs can adopt business-like goals (such as commercialisation or/and conversion from a non-profit to a forprofit legal form); they can also adopt business-like core and support processes (entrepreneurial orientation, professionalisation, business-like philanthropy ....) or develop business-like rhetoric. Such dynamics can be observed in this "health and social-services" ENP cluster; boards, for example, are composed of managers, experts and workers, reflecting very clearly this "entrepreneurial orientation". It is not surprising, in this perspective, that many NPOs and foundations have been identified as social enterprises by local researchers, even though they have far less than $50 \%$ of earned income. 
Testing Major SE Models in CEE 279

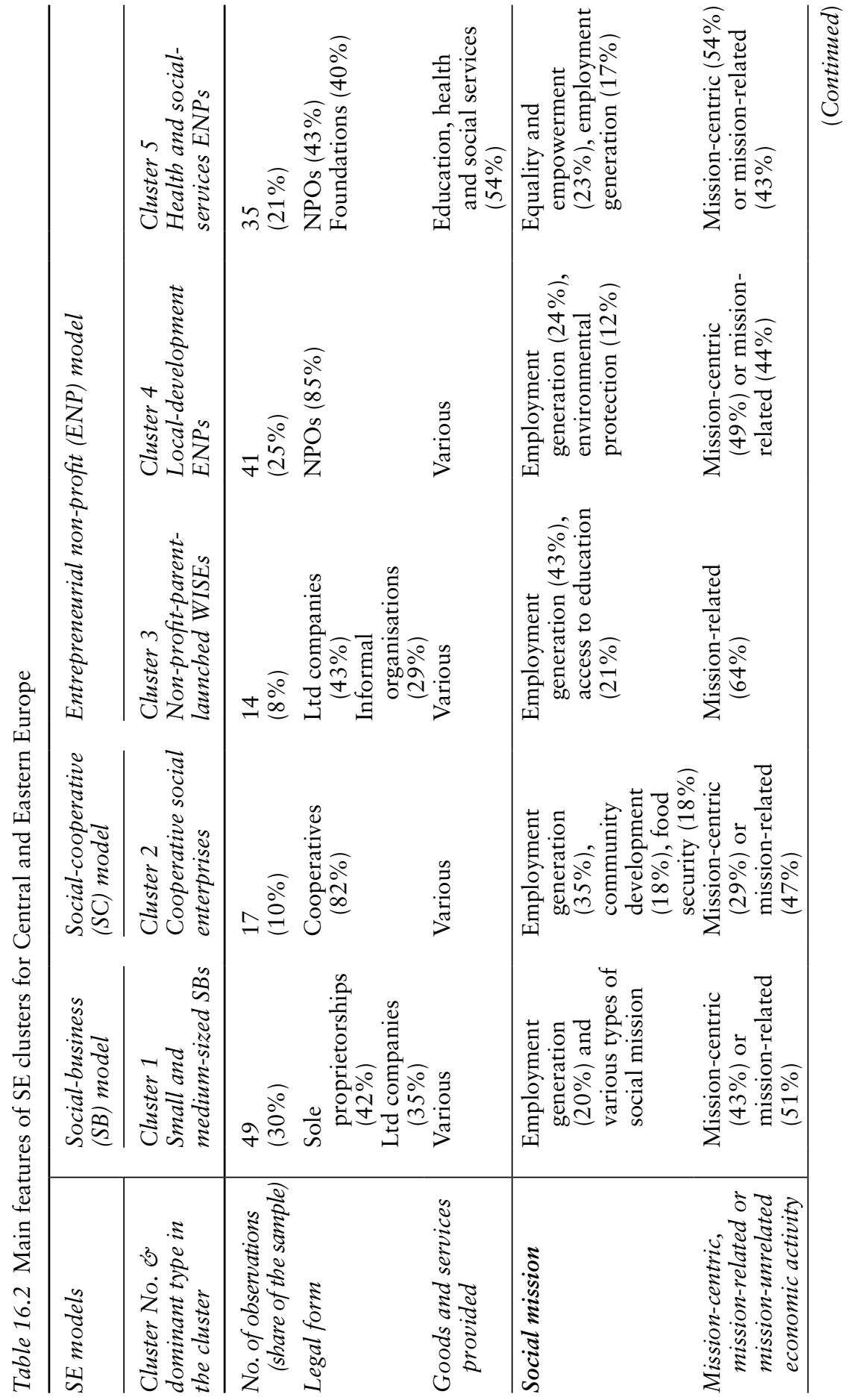




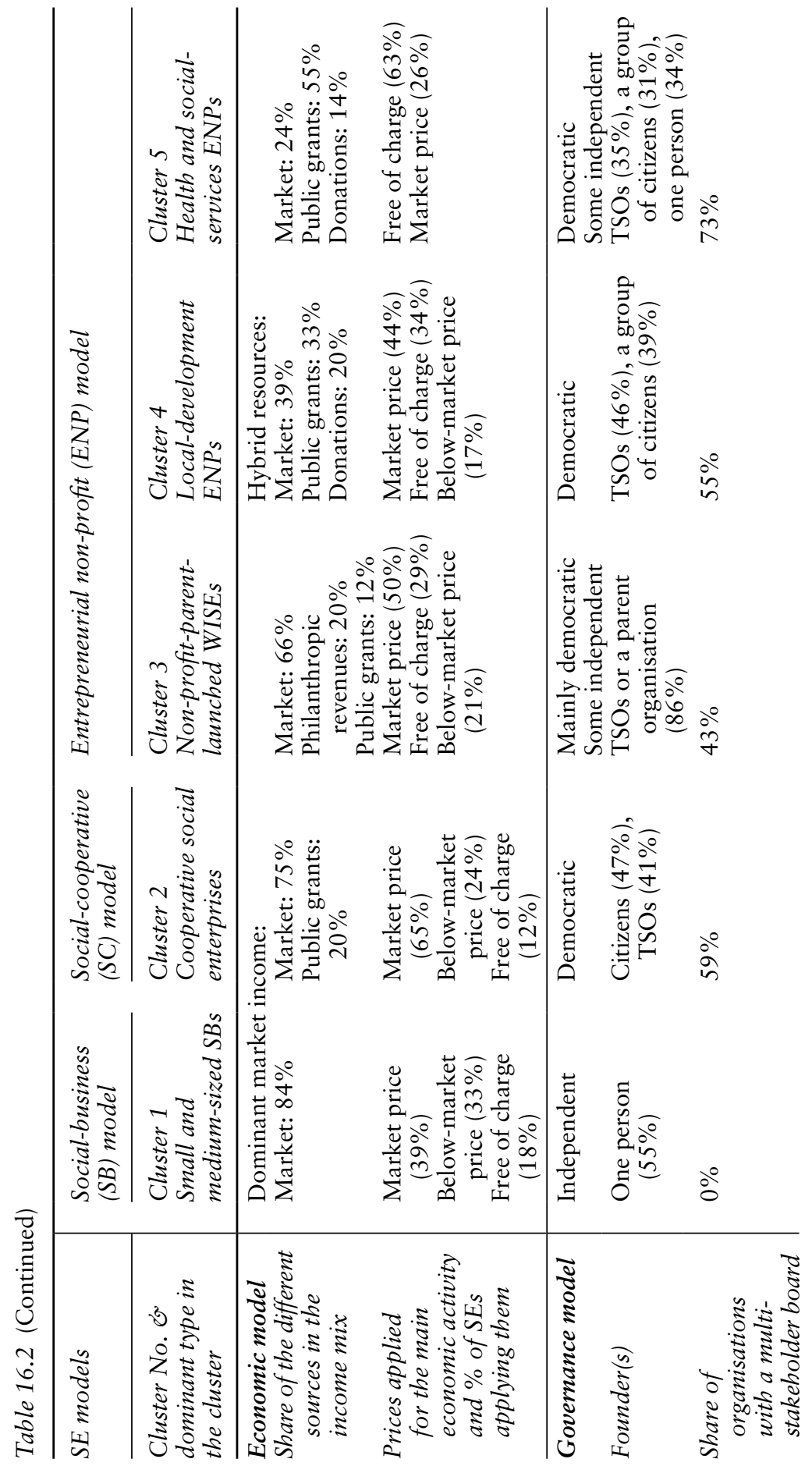



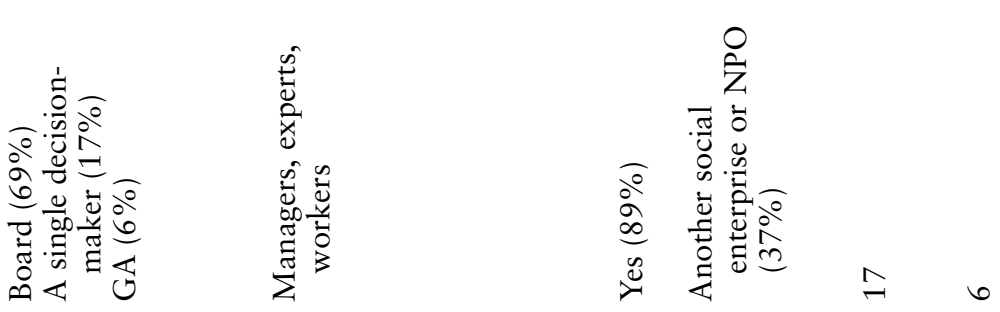

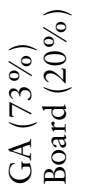
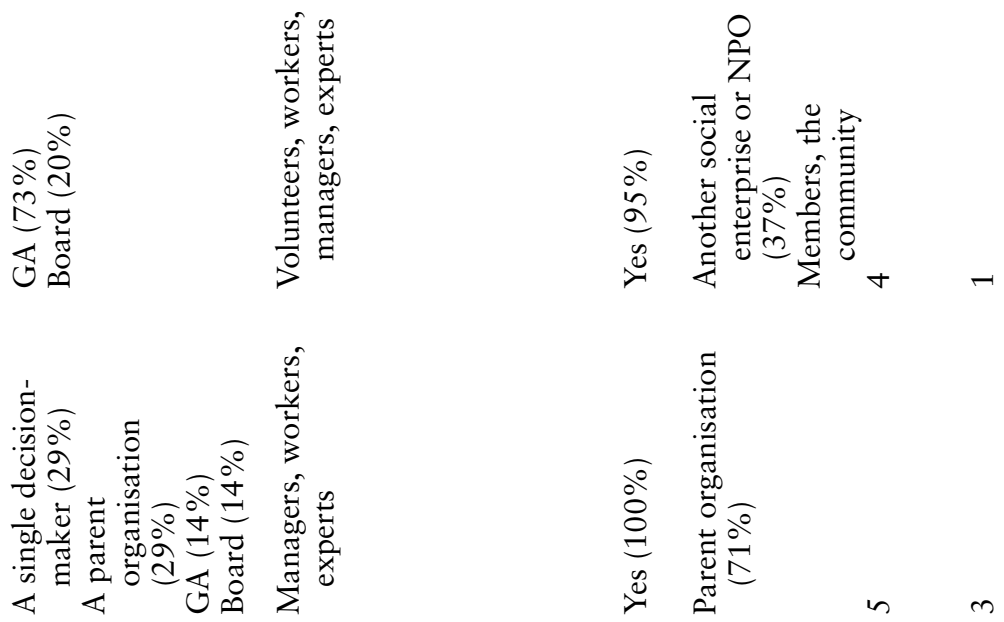

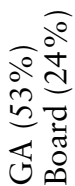
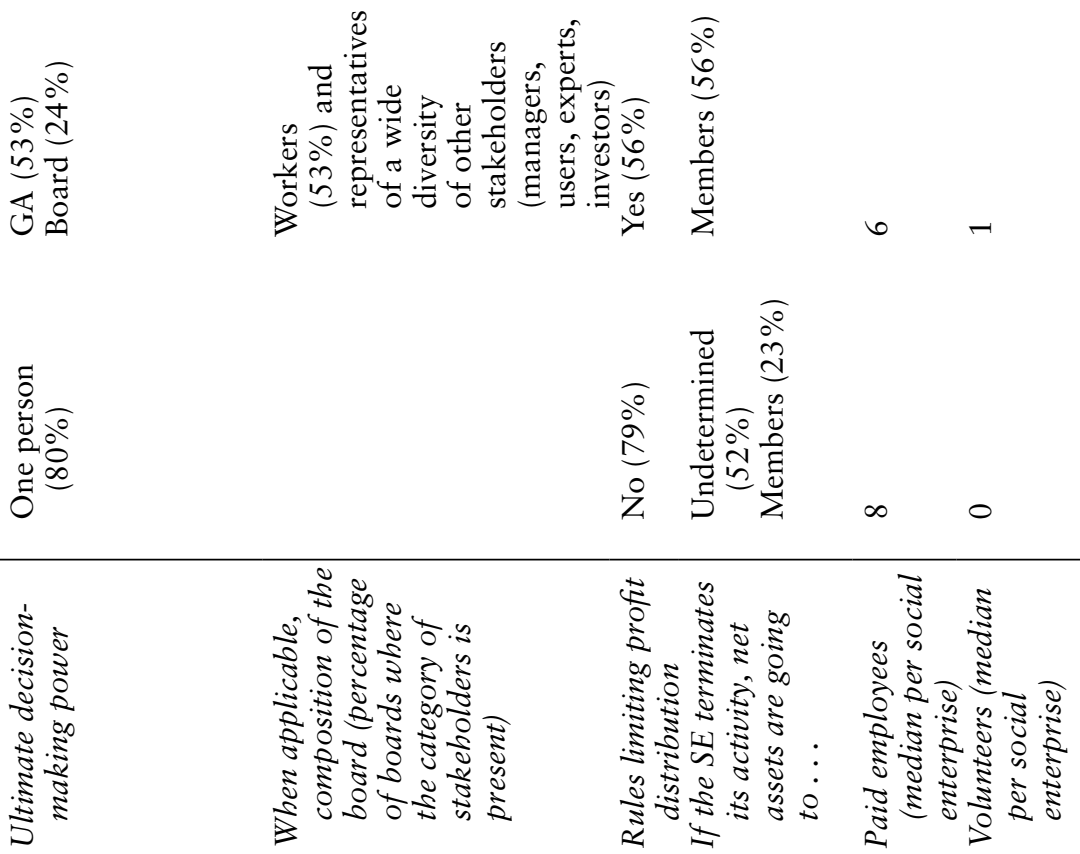
In the local-development ENP cluster (cluster 4), most of the social enterprises adopt the NPO legal form, in which the general assembly generally holds the ultimate decision-making power. In one-fifth of enterprises, this power rests with the board. Boards in cluster 4 are composed of volunteers, managers, experts and workers. Most of the social enterprises in this cluster have been launched by citizens or third-sector organisations. These small-sized NPOs are driven by local-development goals, such as employment generation or environmental protection, and they conduct a wide spectrum of economic activities. They have a markedly hybrid economic model.

The last cluster (cluster 3 ) of this group of entrepreneurial non-profit social enterprises gathers mainly work-integration social enterprises (WISEs). These social enterprises sell a wide variety of goods or services, mainly at market price, and they rely more heavily on earned income than organisations in the two previous clusters. These enterprises' productive activities can be considered as being less often "mission-centric" and more often "mission-related" than those of enterprises in the two clusters previously analysed: indeed, the economic activity is a means to create jobs, whatever the types of products that are commercialised for a population which is much wider than the group of vulnerable workers targeted by the social mission.

A distinctive feature in this cluster is the fact that the most frequent legal form is the limited company, while almost one-third of enterprises are simply informal organisations. This could be accounted for by another interesting feature: almost $90 \%$ of organisations in this cluster have been launched by a parent third-sector organisation. Depending on the type of relations between the social enterprise and its parent non-profit, the former may operate as a formal affiliate of its parent or more informally, without a distinct legal identity. It is why we labelled this cluster "nonprofit-parent-launched WISEs".

These three clusters share enough features to suggest the existence of a deeply rooted "entrepreneurial non-profit SE model", covering a spectrum of non-profit social enterprises. The importance of funds coming from external funding agencies (EU-supported programmes and private foundations) may partly explain why the SE landscape in this region is dominated by the non-profit form, which appears to be the most suitable form to obtain support from some donors (Baturina et al., Chapter 13 in this volume). These external donors-and national policies very strongly fostering "a business approach to nonprofit organisations"-usually focus on some key social challenges, such as employment generation, local development (especially in rural areas) and access to social services (Ciepielewska-Kowalik et al., Chapter 12; Baturina et al., Chapter 13; and Evans et al., Chapter 15 in this volume). 


\subsection{One Cluster Indicating the Existence of a Social-Business Model}

The largest cluster (cluster 1, with 49 observed organisations) mainly gathers sole proprietorships and limited companies, mostly initiated and governed by a single person; this leads us to describe the ownership and governance of these social enterprises as "independent". These enterprises combine a strong business orientation with a social mission. One of the most frequent social missions cited by these social enterprises is employment generation; this constitutes a further sign of the importance attached to this kind of mission in CEE countries-which even leads, in some cases, to conflating social enterprises with WISEs.

Data show that these enterprises produce a diversity of economic goods and services, and that the bulk of their resources $(84 \%)$ comes from the market, although a significant share of these enterprises sell their outputs below market price. They operate with paid workers, and they do not rely on volunteers. This cluster is thus made of small-sized social businesses operating on the market while simultaneously pursuing a social mission.

At first sight, a good deal of the social-business literature emphasises and celebrates initiatives launched by or in partnership with multinational corporations, thereby suggesting that such initiatives tend to be rather large. It is that kind of profile we had in mind when we started to conceptualise the social-business model, but our statistical results actually suggest a very different picture: social businesses are actually rather small enterprises, led by an individual entrepreneur who is the main owner and the dominant decision-maker.

Only $21 \%$ of organisations in this cluster impose rules regarding the distribution of profits, and more than $50 \%$ have no predetermined rule about the distribution of net assets in case the activity is terminated. This is not to say, however, that all or most of the profits are usually distributed to owners: the dominant practice ( $75 \%$ of the cases) is to reinvest at least part of the profits in the social enterprise. In this context, the evolution of the balance between economic and social goals over time raises the question of the social mission's sustainability. It thus seems critical to observe enterprises' actual practices more in depth: To what extent do social and/or environmental dimensions actually dominate the profit motive? Are they not mere instruments to better serve the financial interests of the owner(s)? More generally, under which conditions can a social-value-generating economic activity be considered as an expression of social entrepreneurship?

In any case, at this stage, this cluster provides support to the idea that the social-business model is deeply rooted in SMEs' willingness to generate blended value. The emergence of social enterprises corresponding to 
the social-business model can be explained, in Eastern and Central European countries, by the fact that some external agencies, such as Ashoka or the British council, among others, propose their support to individual social entrepreneurs (Baturina et al., Chapter 13 in this volume).

\subsection{One Cluster Indicating the Existence of a Social-Cooperative SE Model}

Although cluster 2 gathers only $10 \%$ of the whole sample, it has a strong identity from a legal point of view: an overwhelming majority of organisations in this cluster have adopted the form of cooperative. This invites us to look at this cluster as potentially signalling the existence of a "cooperative-type" SE model.

The cooperative model has a very specific history in CEE countries, where this legal form is just starting to arouse interest again. Indeed, although most of these countries had a rich cooperative history before World War II, cooperatives lost their autonomy under state socialism, and they became instruments controlled by the state. Due to this legacy, a negative image is still associated with this sector. However, with the progressive enlargement of the EU, the concept of social economy (which includes cooperatives) gained importance and new legal forms-such as that of social cooperative-were introduced in several countries, including Poland, Hungary, Croatia and Serbia.

Most of the organisations in this cluster have been launched by groups of citizens or third-sector organisations. They display democratic governance structures; workers are present in a majority of boards and so are various other types of stakeholders. If the social enterprise terminates its activity, the net assets are most often transferred to the members.

The social mission and economic activities are clearly interwoven. Organisations serve strong social objectives: they aim mainly at creating jobs for the unemployed or at supporting community development or improving food security. These social enterprises rely mainly on market resources (which represent on average $75 \%$ of their income), but onethird of enterprises sell their products below market price-a fact that reflects their general-interest orientation.

This leads us to conclude that our theorisation of social cooperative as an SE model is supported by empirical evidence. However, this model is still emerging in CEE countries, and this trend is not as strong as what is observed in other regions, such as Western Europe (Defourny et al. 2020).

\section{Conclusion}

The objective of this last chapter was to test the typology of SE models that we had previously put forward on a theoretical basis (Defourny 
and Nyssens 2017). The major finding is that three of our four theorised SE models are strongly supported by empirical evidence: the existence of a social-business model, a social-cooperative model and an entrepreneurial non-profit model is fully confirmed by the examination of the five clusters resulting from the statistical analysis of data about CEE social enterprises.

When adding results from the other regions of the world to the picture, we are able to confirm the relevance of these three SE models, both across countries within each region ${ }^{8}$ and across regions. More precisely, these three models are found in 39 countries out of 43 , and applying the statistical treatment described in Section 2 to the data about all the 721 surveyed social enterprises actually yielded the same major results. ${ }^{9}$ Referring to the hypothesis that we had put forward in this chapter's introduction, we can now assert that our typology of SE models is neither country-specific nor even, more broadly, region-specific.

At this final stage, it makes sense to raise again the question which has been an underlying thread of the whole ICSEM Project: to what extent and why is it important to apprehend and highlight the diversity of SE models?

Let us address this central question in terms of policy implications, not just for institutional policymakers but also to feed debates in which all types of actors and stakeholders may get involved. Instead of presenting a menu of "best practices" like some experts and consulting companies, we prefer to identify some important risks, limitations or even traps to be avoided.

\section{The Impossible Consensual Definition}

The first and most obvious trap would be to keep devoting a lot of efforts, time, energy and skills to the search for a "consensual definition of social enterprise". Indeed, achieving this goal is often perceived as a necessary condition for any advancement of the SE field towards clarity (of borders), measurability (of inputs and outputs) and legitimacy (in the eyes of all actors); but those who cannot live with SE diversity will face major difficulties when discovering that many social enterprises are actually hybrid organisations, living on or close to boundaries. Obstacles are getting even greater when it comes to estimating employment or other key variables in social enterprises: there is a high risk to focus only on SE types targeted by some public schemes, social enterprises registered in the framework of some precise legislation, or social enterprises accredited to be eligible for some forms of support, among others.

In Central and Eastern Europe, new legal forms, decrees or/and national strategies have emerged since the beginning of the century to promote social enterprise; this was, for example, the case in Albania, Bulgaria, Hungary, Latvia, Lithuania, Poland, Romania and Slovenia, to 
name just a few (European Commission 2020). Obviously, none of these frameworks embraces the whole SE field; on the contrary, as highlighted by the European Commission (2020: 35), social enterprises tend to be narrowly understood through the lenses of these legal frameworks.

\section{Isomorphic Pressures on WISEs}

Most of these legal forms are oriented towards the same social mission, namely the social and economic integration of low-skilled workers, handicapped persons, long-term unemployed or other disadvantaged groups. This is clearly confirmed by our statistical results, which show the prevalence of the employment-generation mission across all SE models in Central and Eastern Europe.

Such a focus on the employment of disadvantaged groups is tempting for all actors when public funds are allocated and legal frameworks designed to promote such initiatives because work integration ranks very high on the political agenda. In such context, it may even happen that public authorities impose one or a few very precise type(s) of WISE framework, while leaving very little space for autonomy to social enterprises (in Hungary, for example, social cooperatives cannot be fully independent from local municipalities or from state-accredited charities). Therefore, a second trap, closely linked to the first one, is to narrow the understanding of social enterprise to those initiatives that pursue a goal of employment generation and to overlook all other types of social enterprise.

\section{Isomorphic Pressures From External Funders}

As analysed in various chapters of this book (see Chapters 12 and 13), the SE programmes developed by external donors have deeply shaped the discourse on social enterprise in Central and Eastern Europe. Against such background, it often proves tempting to import SE models supported by these external public bodies (the British Council, EU Structural Funds, UN programmes) or private agencies (Ashoka, NESsT, Yunus Social Business).

The dominant discourse conveyed by these donors is inspired by the "earned-income" school of thought, which defines social enterprise as "a market solution to a social problem". As underlined by Baturina and his co-authors in Chapter 13 of this volume, such an approach can legitimise at least a partial withdrawal of the state from social-services provision and place (too) high expectations on civil society' resources to achieve key public missions. However, it is striking to observe that almost $50 \%$ of the social enterprises in the ICSEM sample for CEE countries have less than $50 \%$ of market income.

Some of these external discourses also tend to point out a "weak associative and cooperative tradition" in Central and Eastern Europe 
(European Commission 2020). Once more, our data provide another picture: $70 \%$ of social enterprises are converging to either the socialcooperative model or the entrepreneurial non-profit model. Civil society does not appear as weak in CEE countries as it is commonly assumed. Indeed, many post-communist countries have vigorous public spheres and active civil-society organisations. However, the institutional environment may hinder these organisations' advocacy role, and state/civil-society relationships are rather characterised by clientelism than by partnership (Foa and Ekiert 2017). Regarding the cooperative movement, as already highlighted, several CEE countries had a lively cooperative movement before World War II. Nowadays, although some mistrust in cooperatives still persists as part of the legacy of state socialism, the social-cooperative model is starting to arouse interest in several countries.

Allowing the field to be shaped by external discourses would be a third trap. Without denying that external support has been a key driver for the development of the SE ecosystem in Eastern and Central Europe, SE policy frameworks would benefit from relying more intensively on endogenous drivers, embedded in clear internal policy strategies (Cvejić et al., Chapter 14 in this volume).

Finally, orienting many efforts towards "catching up" with Westernframed SE models would constitute a fourth trap, specific to CEE countries. These efforts would probably only "produce short-term and often vague effects, which [would contribute] to the development of the myth of social enterprise and social entrepreneurship" (Cvejić et al., Chapter 14 in this volume) as outstanding solutions to "fill the gap" with the West.

\section{Towards a Plurality of Endogenous SE Ecosystems}

Our results suggest that social enterprises stem from most, if not all, parts of the economy and can be related to different organisational backgrounds-namely the non-profit, the cooperative and the traditional business sectors. Our empirical analysis does not confirm the existence of a public-type SE model through the identification of a distinct cluster, but in the cluster gathering parent-launched work-integration social enterprises, $30 \%$ of enterprises involve a governmental agency among their founding members, and some country contributions clearly identify this model; this is, for example, the case in Estonia (Evans et al., Chapter 15 in this volume).

Instead of leading towards limitations or traps such as those just listed, the diversity of SE models should be seen and exploited as a key asset. In today's context, indeed, the complexity of social or societal challenges calls for a sound awareness of all models' strengths and weaknesses and for collaboration, synergies and partnerships among social enterprises. 
Social enterprises are influenced by external factors, but they can also in turn contribute to shaping their institutional environment. Social enterprises' institutional dimension - that is, their potential role in the development of norms and regulations-should be acknowledged both at the level of the organisation and beyond, through the "institutional work" of all actors. Through their innovative dynamics in many fields of activities, these initiatives indeed bear a transformative potential for the whole economy, in search for sustainable models. The challenge is, therefore, to take the full measure of their contribution and broaden their influence.

\section{Notes}

1. In their classic survey of literature on social entrepreneurship, Dacin et al. (2011) listed some 80 references, among which only one referred to social enterprise in its title. On the basis of 307 documents selected because they referred to at least one of the notions of "social enterprise", "social entrepreneurship" and "social entrepreneur" such as they understood them, Alegre et al. (2017) developed a citation map and a cluster analysis of definitions; they came out with five quite distinct groups, among which three focused on social entrepreneurship and a single one, quite isolated, focused on defining social enterprise. For their part, Sassmannshausen and Volkmann (2018) provided an overview of the state of art of research on social entrepreneurship and its establishment as an academic field. See also the Journal of Social Entrepreneurship, launched in 2010.

2. See the Social Enterprise Journal, launched in 2005; most of the research carried out by or in relation to the EMES International Research Network since the late 1990s; and the recent EU report titled Social Enterprises and Their Ecosystems in Europe (European Commission 2020).

3. The work coordinated by Nyssens (2006) relied on a common survey covering 162 work-integration social enterprises (WISEs) from eleven EU countries and almost 1,000 "WISE participants", that is, persons engaged in work-integration trajectories.

4. Kerlin's typology is also rooted in a theory trying to explain the existence and the place of the non-profit (third) sector. However, it is not confronted with empirical evidence at the enterprise level.

5. In a few countries where the notion of social enterprise is defined, for instance through a law, the definition does not generally enable an uncontested mapping and statistical analysis, because such a legal approach is often deemed too large or too narrow.

6. Results for Western European countries are presented in the ICSEM book which is devoted to this part of Europe (Defourny and Nyssens 2021). Results for Latin America and Asia are presented in the first two ICSEM books, that is, respectively, Gaiger et al. (2019) and Bidet and Defourny (2019).

7. One more cluster, gathering eight social enterprises, was identified, but it was dropped because these social enterprises could be considered as "outliers".

8. See the other three books that resulted from the ICSEM Project, and in particular Chapter 20 in Defourny and Nyssens (2021), Chapter 16 in Bidet and Defourny (2019) and Chapter 11 in Gaiger et al. (2019), for results about, respectively, Western Europe, Asia and Latin America. 
9. This global statistical analysis was first carried out and reported by Defourny et al. (2019) in an ICSEM Working Paper and was then published in Nonprofit and Voluntary Sector Quarterly (Defourny et al. 2020).

\section{References}

Alegre, I., Kislenko, S. \& Berbegal-Mirabent, J. (2017) “Organized chaos: Mapping the definitions of social entrepreneurship", Journal of Social Entrepreneurship, Vol. 8, No. 2, pp. 248-64.

Alter, K. (2007) Social Enterprise Typology, Friendswood: Virtue Ventures LLC.

Bidet, E. \& Defourny, J. (eds) (2019) Social Enterprise in Asia. Theory, Models and Practice, London and New York: Routledge.

Borzaga, C. \& Defourny, J. (eds) (2001) The Emergence of Social Enterprise, London and New York: Routledge.

Borzaga, C., Galera, G. \& Nogales, R. (eds) (2008) Social Enterprise: A New Model for Poverty Reduction and Employment Generation, Bratislava: United Nations Development Programme.

Dacin, M. T., Dacin, P. A. \& Tracey, P. (2011) "Social entrepreneurship: A critique and future directions”, Organization Science, Vol. 22, No. 5, pp. 1203-13.

Defourny, J. \& Kim, S.-Y. (2011) "Emerging models of social enterprise in Eastern Asia: A cross-country analysis", Social Enterprise Journal, Vol. 7, No. 1, pp. 86-111.

Defourny, J. \& Nyssens, M. (2010) “Conceptions of social enterprise and social entrepreneurship in Europe and the United States: Convergences and divergences", Journal of Social Entrepreneurship, Vol. 1, No. 1, pp. 32-53.

Defourny, J. \& Nyssens, M. (2017) "Fundamentals for an international typology of social enterprise models", Voluntas, Vol. 28, No. 6, pp. 2469-97.

Defourny, J. \& Nyssens, M. (eds) (2021) Social Enterprise in Western Europe. Theory, Models and Practice, London and New York: Routledge.

Defourny, J., Nyssens, M. \& Brolis, O. (2019) "Mapping and testing social enterprise models across the world: Evidence from the 'international comparative social enterprise models (ICSEM) project' ", ICSEM Working Papers, No. 50, Liege: The International Comparative Social Enterprise Models (ICSEM) Project.

Defourny, J., Nyssens, M. \& Brolis, O. (2020) “Testing social enterprise models across the world: Evidence from the 'international comparative social enterprise models' (ICSEM) project”, Nonprofit and Voluntary Sector Quarterly. First published online September 2020. Available HTTP: https://doi.org/ $10.1177 / 0899764020959470$

European Commission (2020) Social Enterprises and Their Ecosystems in Europe, Comparative Synthesis Report (Authors: Borzaga, C., Galera, G., Franchini, B., Chiomento, S., Nogales, R. \& Carini, C.), Luxembourg: Publications Office of the European Union.

Foa, R. S. \& Ekiert, G. (2017) "The weakness of post-communist civil society reassessed", European Journal of Political Research, Vol. 56, No. 2, pp. 419-39.

Gaiger, L. I., Nyssens, M. \& Wanderley, F. (eds) (2019) Social Enterprise in Latin America Theory, Models and Practice, London and New York: Routledge. 
Gordon, M. (2015) “A typology of social enterprise traditions”, ICSEM Working Papers, No. 18, Liege: The International Comparative Social Enterprise Models (ICSEM) Project.

Gui, B. (1991) “The economic rationale for the third sector", Annals of Public and Cooperative Economics, Vol. 62, No. 4, pp. 551-72.

Hansmann, H. (1996) The Ownership of Enterprise, Cambridge: Harvard University Press.

Kerlin, J. A. (2013) "Defining social enterprise across different contexts: A conceptual framework based on institutional factors", Nonprofit and Voluntary Sector Quarterly, Vol. 12, No. 1, pp. 84-108.

Kerlin, J. A. (ed) (2017) Shaping Social Enterprise: Understanding Institutional Context and Influence, London: Emerald Publishing Group.

Maier, F., Meyer, M. \& Steinbereithner, M. (2016) "Nonprofit organizations becoming business-like: A systematic review", Nonprofit and Voluntary Sector Quarterly, Vol. 45, No. 1, pp. 64-86.

McMurtry, J. J. \& Brouard, F. (2015) "Social enterprises in Canada: An introduction", Canadian Journal of Nonprofit and Social Economy Research, Vol. 6, No. 1, pp. 6-17.

Nyssens, M. (ed) (2006) Social Enterprise. At the Crossroad of Market, Public Policies and Civil Society, London: Routledge.

Salamon, L., Sokolowski, W. \& Anheier, H. (2000) "Social origins of civil society: An overview", Working Paper of the Johns Hopkins Comparative Nonprofit Sector Project, No. 38, Baltimore, MD: The Johns Hopkins Center for Civil Society Studies.

Santos, F. M. (2012) “A positive theory of social entrepreneurship”, Journal of Business Ethics, Vol. 111, No. 3, pp. 335-51.

Sassmannshausen, S. \& Volkmann, C. (2018) "The scientometrics of social entrepreneurship and its establishment as an academic field", Journal of Small Business Management, Vol. 56, No. 2, pp. 251-73.

Spear, R., Cornforth, C. \& Aiken, M. (2009) "The governance challenges of social enterprises: Evidence from a UK empirical study", Annals of Public and Cooperative Economics, Vol. 80, No. 2, pp. 247-73.

Teasdale, S. (2012) "What's in a name? Making sense of social enterprise discourses", Public Policy and Administration, Vol. 27, No. 2, pp. 99-119.

Young, D., Searing, E. \& Brewer, C. (eds) (2016) The Social Enterprise Zoo, Cheltenham: Edward Elgar Publishing. 